\title{
Ketercapaian Sasaran 4K dalam Pelaksanaan Rencana Pengamanan Air Minum (RPAM) di PDAM Tirta Dharma Kota Malang
}

\author{
DEWI SHANTY' ${ }^{1}$, RACHMAWATI S.DJ ${ }^{1}$
}

1. Jurusan Teknik Lingkungan, Fakultas Teknik Sipil dan Perencanaan, Institut Teknologi Nasional, Bandung

Email:shantydewis@ymail.com

\begin{abstract}
ABSTRAK
PDAM Kota Malang sebagai sarana penyedia air minum di Kota Malang, diharapkan mampu mencapai target Rencana Pembangunan Jangka Menengah Nasional (RPJMN) 2015-2019, yaitu akses terhadap air minum mencapai 100\% di tahun 2019. Upaya yang dapat dilakukan untuk mencapai target tersebut, yaitu melalui Rencana Pengamanan Air Minum (RPAM), dengan memperhatikan sasaran aspek $4 K$ (kualitas, kuantitas, kontinuitas, dan keterjangkauan). Sasaran $4 K$ tersebut, yaitu K1 sebagai acuan air minum yang layak dikonsumsi, K2 sebagai jumlah air minimum yang dikonsumsi masyarakat dengan memperhitungkan kehilangan air, K3 sebagai acuan pengaliran tak terputus selama 24 jam, dan $K 4$ sebagai kesanggupan masyarakat untuk membayar harga air sesuai dengan tarif air yang telah diberlakukanberdasarkan peraturan yang dipersyaratkan. Hasil evaluasi menunjukkan PDAM Kota Malang telah mencapai sasaran 4K dan mampu melaksanakan RPAM. Hal tersebut didukung oleh sistem online yang telah dikembangkan untuk menjamin keamanan pendistribusian air minum kepada masyarakat.
\end{abstract}

Kata kunci: PDAM Kota Malang, RPAM, Sasaran $4 K$

\begin{abstract}
PDAM Kota Malang as a drinking water supply in Malang City, is expected to reach the target of National Medium Term Development Plan (RPJMN) 20152019, that is access to drinking water reaches $100 \%$ in 2019. The efforts that can be conducted to achieve the target through the Drinking Water Security Plan (RPAM), by focusing on $4 K$ aspects(quality, quantity, continuity and affordability). The $4 K$ aspects, such as $K 1$ as a reference for drinking water that is suitable for consumption, $K 2$ as the minimum amount of water consumed by the community taking into water losses, $K 3$ as a reference for uninterrupted for 24 hours, and $K 4$ as the ability of the community to pay the price of water based on the regulations required. The evaluation results show that PDAM Kota Malang reached the $4 K$ aspects and be able to implement RPAM. This is supported by an online system that has been developed to safe the distribution of drinking water to the public.
\end{abstract}

Keywords: PDAM Kota Malang, RPAM, 4K Aspects 


\section{PENDAHULUAN}

Berdasarkan Peraturan Daerah Kotamadya Tingkat II Malang Nomor 11 Tahun 1974 tentang Perusahaan Daerah Air Minum (PDAM) Kodya Dati II Malang, PDAM Kota Malang didirikan sebagai sarana penyedia kebutuhan air minum di Kota Malang; sehingga PDAM Kota Malang harus memenuhi target Rencana Pembangunan Jangka Menengah Nasional (RPJMN) 20152019. Target tersebut menyatakan bahwa pada tahun 2019 akses terhadap air minum harus mencapai 100\%; dimana air minum yang dihasilkan harus aman untuk dikonsumsi masyarakat. Cakupan pelayanan PDAM Kota Malangper Maret 2018 mencapai 92\%(Suryo, 2018) dari jumlah penduduk Kota Malang sebanyak 906.347 jiwa (Dinas Kependudukan dan Pencatatan Sipil Kota Malang, 2018). Jumlah pelanggan PDAM Kota Malang mencapai 157.492 pelanggan yang tersebar di 5 (lima) kecamatan, yaitu Kecamatan Blimbing; Kecamatan Kedungkandang; Kecamatan Klojen; Kecamatan Lowokwaru; dan Kecamatan Sukun (PDAM Kota Malang, 2016).

Salah satu upaya yang dilakukan untuk mencapai target RPJMN tersebut, yaitu melalui Rencana Pengamanan Air Minum (RPAM); dimana RPAM tersebut merupakan adopsi dari Water Safety Plan (WSP)yang dikembangkan oleh World Health ofOrganization (WHO). RPAM yang diterapkan di PDAM dilakukan sebagai upaya pengamanan terhadap air minum berdasarkan capaian aspek 4K yang dipersyaratkan (Direktorat PU Cipta Karya, 2012).

RPAM di Indonesia terdiri dari RPAM Sumber, RPAM Operator, dan RPAM Konsumen. Pelaksanaan RPAM Operator dilakukan PDAM Kota Malang sejak tahun 2013 sebagai pendekatan analisis dan manajemen risikoakibattimbulnya setiap kejadian bahaya; sehingga maksud dalam penelitian ini, yaitu untuk melihat tercapainya sasaran 4K dalam RPAM dan dilakukan evaluasi berdasarkan penerapan yang telah dilakukan PDAM Kota Malang di lapangan.

\section{METODOLOGI}

\subsection{Studi Literatur}

Studi literatur digunakan sebagai acuan dalam setiap tahap penelitian ini. Bahan studi literatur tersebut diperoleh dari berbagai sumber, seperti jurnal, buku, peraturan perundangan, dokumen PDAM, dan internet.

\subsection{Metode Pengumpulan Data}

Data yang dikumpulkan untuk penelitian ini, adalah data primer dan data sekunder.

a. Data Primer

Metode pengumpulan data primer, yaitu berupa hasil pengukuran langsung di lapangan, hasil diskusi atau wawancara, dan hasil perhitungan. Pengukuran langsung di lapangan terkait kualitas (K1), dilakukan hanya di Pompa Wendit II dan III, salah satu Zona Air Minum Prima (ZAMP), jaringan distribusi pelanggan, dan reservoir; sedangkan terkait kontinuitas (K3), pengukuran tekanan dilakukan di jaringan distribusi pelanggan, yaitu di jalan raya dan komplek perumahan. Hal tersebut dikarenakan kemudahan pencapaian kedua lokasi saat observasi.

b. Data Sekunder

Metode pengumpulan data sekunder, yaitu berupa studi literatur yang berhubungan dengan penelitian dan dokumen PDAM Kota Malang; seperti dokumen RPAM, referensi berbagai sumber, dan peraturan perundangan terkait penelitian sebagai bahan evaluasi. 


\subsection{Metode Analisis Data}

Metode analisis data yang digunakan merupakan metode deskriptif, yaitu mendeskripsikan hasil evaluasi berdasarkan kondisi yang ada. Analisis terhadap data primer dilengkapi dengan dokumentasi sebagai bukti pelaksanaan di lapangan; sedangkan data kualitatif sekunder berdasarkan dokumen RPAM PDAM Kota Malang untuk melihat ketercapaiannya terhadap sasaran $4 \mathrm{~K}$.

\section{HASIL DAN PEMBAHASAN}

Tujuan pelaksanaan RPAM yang dilakukan oleh PDAM Kota Malang, yaitu untuk meningkatkan efisiensi dan mencapai efektifitas pelayanan air minum kepada masyarakat dengan pencapaian terhadap aspek 4K. Aspek tersebut didasarkan terhadap kondisi penyediaan air minum di Indonesia yang masih kurang baik. Permasalahan yang dihadapi, diantaranya keamanan air minum dari segi kualitas, kuantitas yang masih kurang untuk memenuhi kebutuhan masyarakat, kontinuitas belum mencapai pengaliran 24 jam, dan keterjangkauan sebagai tingkat kesetaraan perekonomian masyarakat dalam mendapatkan akses air minum (Adiyanti, 2016). Data produksi dan distribusi PDAM Kota Malang tahun 2013 - September 2017 dapat dilihat pada Tabel 1.

Tabel 1. Data Produksi dan Distribusi PDAM Kota Malang

\begin{tabular}{|c|c|c|c|c|c|c|c|}
\hline No & Data yg dibutuhkan & Satuan & 2013 & 2014 & 2015 & 2016 & $\begin{array}{c}\text { September } \\
2017\end{array}$ \\
\hline I. & K1-KUALITAS & & & & & & \\
\hline 1. & $\begin{array}{l}\text { Harga Air Minum } \\
\text { (ZAMP)* }\end{array}$ & $\mathrm{Rp} / \mathrm{m}^{3}$ & 2.500 & 2.500 & 2.800 & 3.000 & 3.200 \\
\hline 2. & Harga Air Bersih & $\mathrm{Rp} / \mathrm{m}^{3}$ & 2.500 & 2.500 & 2.800 & 3.000 & 3.200 \\
\hline II. & K2-KUANTITAS & & & & & & \\
\hline 1. & Debit Air Baku (inlet) & $\mathrm{m}^{3} /$ detik & 1,67 & 1,67 & 1,68 & 1,79 & 1,68 \\
\hline 2. & Debit Air Produksi & $\mathrm{m}^{3} /$ detik & 1,29 & 1,36 & 1,37 & 1,44 & 1,57 \\
\hline 3. & $\begin{array}{l}\text { Kehilangan Air di } \\
\text { Produksi }\end{array}$ & $\%$ & 22,75 & 18,56 & 18,45 & 19,55 & 6,55 \\
\hline 4. & Debit Air Terjual & $\mathrm{m}^{3} /$ detik & 0,84 & 1,04 & 0,98 & 1,04 & 1,31 \\
\hline 5. & $\begin{array}{l}\text { Kehilangan Air di } \\
\text { Distribusi }\end{array}$ & $\%$ & 34,88 & 23,53 & 28,47 & 27,78 & 16,56 \\
\hline \multirow{2}{*}{6.} & $\begin{array}{l}\text { Jumlah KK yang }<10 \\
\text { m3/bulan }\end{array}$ & KK & 45.425 & 47.413 & 50.785 & 56.306 & 54.795 \\
\hline & $\begin{array}{l}\text { Jumlah KK yang } \geq 10 \\
\text { m3/bulan }\end{array}$ & KK & 80.189 & 87.217 & 95.256 & 96.493 & 100.910 \\
\hline 7. & Jumlah Total Pelanggan & KK & 125.614 & 134.630 & 146.041 & 152.799 & 155.705 \\
\hline III. & K3-KONTINUITAS & & & & & & \\
\hline 1. & Lama Pelayanan & jam/hari & 24 & 24 & 24 & 24 & 24 \\
\hline 2. & $\begin{array}{l}\text { Jumlah KK dengan } \\
\text { Tekanan <0,3 dan 0,5 } \\
\text { bar }\end{array}$ & KK & tidak ada & tidak ada & tidak ada & tidak ada & tidak ada \\
\hline IV. & K4-KETERJANGKAUAN & & & & & & \\
\hline 1. & $\begin{array}{l}\text { Upah Minimum Kota } \\
\text { Malang (UMK) }\end{array}$ & Rp/bulan & 1.340 .300 & 1.587 .000 & 1.882 .250 & 2.099 .000 & 2.272 .170 \\
\hline 2. & $4 \%$ UMK & Rp/bulan & 53.612 & 63.480 & 75.290 & 83.960 & 90.887 \\
\hline
\end{tabular}

Keterangan: *Zona Air Minum Prima

\subsection{Kualitas (K1)}

Sumber air baku yang digunakan PDAM Kota Malang berasal dari sumber mata air; sehingga tidak perlu dilakukan pengolahan yang rumit agar air tersebut layak menjadi air minum dengan menggunakan proses desinfeksi. Proses tersebut menggunakan gas chlor agar kandungan berbahaya yang ada dalam air dapat disisihkan, sehingga tidak menimbulkan 
gangguan pada kesehatan manusia. Selain pengolahan yang tidak rumit, mata air sebagai sumber air baku dikatakan baik secara kualitas (Arthana, 2007). Dari proses desinfeksi, diharapkan dapat menghasilkan mutu air sesuai dengan standar air minum yang ditetapkan berdasarkan Peraturan Menteri Kesehatan Nomor 492 Tahun 2010 tentang Persyaratan Kualitas Air Minum. Hasil pemeriksaan di lapangan untuk beberapa lokasi dapat dilihat pada Tabel 2.

Tabel 2. Hasil Pemeriksaan di Lapangan

\begin{tabular}{|c|c|c|c|c|c|}
\hline No. & Lokasi Pengukuran & Parameter & Satuan & Nilai & Standar \\
\hline \multirow{4}{*}{1} & \multirow{4}{*}{ Pompa Wendit II \& III } & $\mathrm{pH}$ & - & 6,9 & $6,5-8,5$ \\
\hline & & Kekeruhan & NTU & 0,39 & 5 \\
\hline & & Suhu & $\mathrm{C}$ & 28 & suhu udara \pm 3 \\
\hline & & Sisa khlor & $\mathrm{mg} / \mathrm{L}$ & $0,45-0,46$ & $0,2-0,5$ \\
\hline \multirow{4}{*}{2} & \multirow{4}{*}{$\begin{array}{l}\text { Jaringan Distribusi } \\
\text { Pelanggan (Jalan Raya) }\end{array}$} & Tekanan & bar & 2,2 & minimal 0,5 \\
\hline & & $\mathrm{pH}$ & - & 7 & $6,5-8,5$ \\
\hline & & Kekeruhan & NTU & 0,16 & 5 \\
\hline & & Suhu & $\mathrm{C}$ & 27 & suhu udara \pm 3 \\
\hline 3 & $\begin{array}{l}\text { Jaringan Distribusi } \\
\text { Pelanggan (Komplek } \\
\text { Perumahan) }\end{array}$ & Tekanan & bar & 1,4 & minimal 0,5 \\
\hline \multirow{3}{*}{4} & \multirow{3}{*}{$\begin{array}{l}\text { Zona Air Minum Prima } \\
\text { (ZAMP) Masjid }\end{array}$} & $\mathrm{pH}$ & - & 6,9 & $6,5-8,5$ \\
\hline & & Kekeruhan & NTU & 0,25 & 5 \\
\hline & & Suhu & $\mathrm{C}$ & 28 & suhu udara \pm 3 \\
\hline \multirow{3}{*}{5} & \multirow{3}{*}{ Reservoir } & $\mathrm{pH}$ & - & 7,8 & $6,5-8,5$ \\
\hline & & Kekeruhan & NTU & 0,04 & 5 \\
\hline & & Suhu & $\mathrm{C}$ & 23 & suhu udara \pm 3 \\
\hline
\end{tabular}

Sumber: Observasi Lapangan, 2017

Pengukuran langsung dilakukan untuk parameter $\mathrm{pH}$, kekeruhan, suhu, dan tekanan di titik kritis(Gambar 1); sedangkan sisa khlor dapat diakses secara online melalui website PDAM Kota Malang, yang menunjukkan indikator air siap minum. Dari hasil pengukuran tersebut, diperoleh bahwa air yang diproduksi PDAM Kota Malang telah memenuhi standar kualitas air minum yang dipersyaratkan, sehingga sudah layak untuk dikonsumsi.

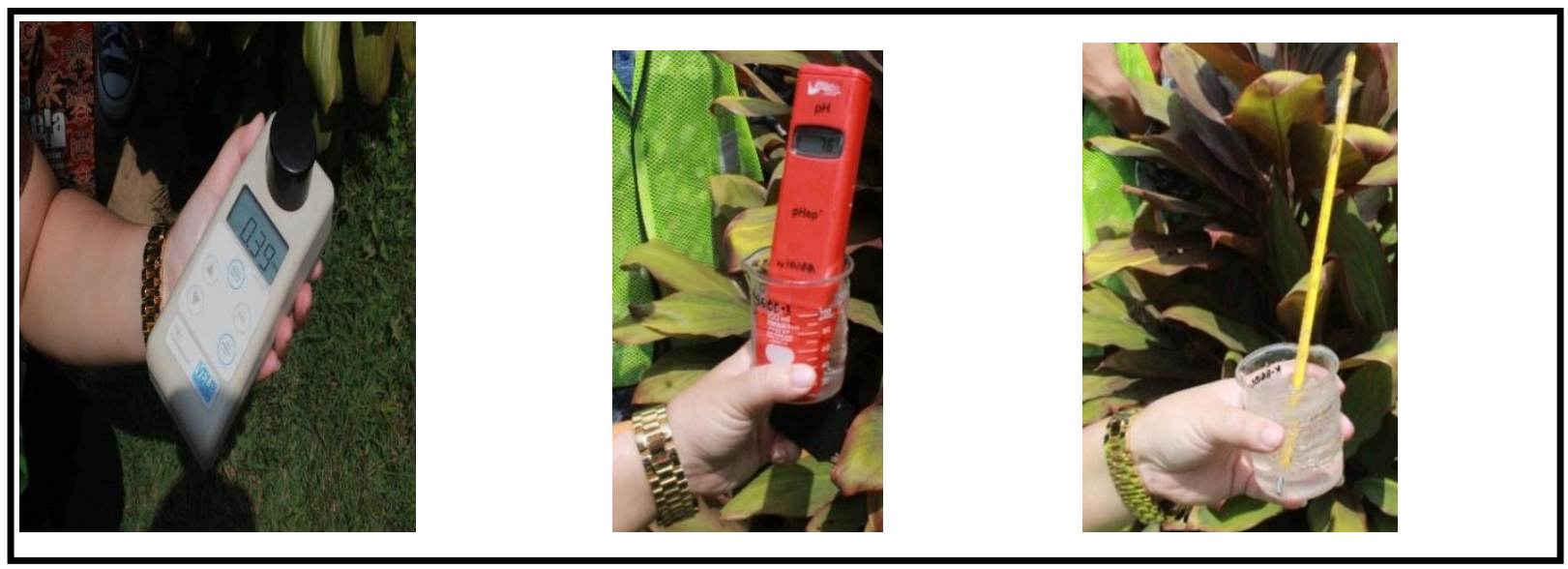

Gambar 1.Pengukuran Langsung di Lapangan

(Sumber: Observasi Lapangan, 2017) 
Terdapat lima besar kejadian bahaya dan risiko yang ditimbulkan dan sangat berpengaruh terhadap kualitas air di wilayah sumber air bakuPDAM Kota Malang(Tabel 3).

Tabel 3. Kejadian Bahaya dan Risiko di Sumber

\begin{tabular}{cll}
\hline No. & \multicolumn{1}{c}{ Kejadian Bahaya } & \multicolumn{1}{c}{ Risiko } \\
\hline 1. & Masuknya ikan/sampah ke dalam bak pompa & $\begin{array}{l}\text { Berkurangnya resapan air tanah, } \\
\text { air keruh }\end{array}$ \\
\hline 2. & $\begin{array}{l}\text { Bak penampung air baku tercemar oleh aktivitas } \\
\text { rekreasi }\end{array}$ & Penurunan kualitas air baku \\
\hline 3. & Curah hujan yang tinggi & Banjir \\
\hline 4. & Masuknya limpasan air sungai & Air keruh \\
\hline 5. & $\begin{array}{l}\text { Masuknya limbah dari kegiatan domestik dan } \\
\text { pertanian }\end{array}$ & $\begin{array}{l}\text { Meningkatnya kadar pencemar di } \\
\text { dalam air baku }\end{array}$ \\
\hline
\end{tabular}

Sumber: PDAM Kota Malang, 2013

Upaya yang telah dilakukan PDAM Kota Malanguntuk menanggulangi dan meminimalkan risikoterhadap aspek kualitas(Gambar 2), diantaranya :

- pemasanganstrainerinlet di bak pompa;

- pemantauan level air, pembersihan sampah, dan early warning system untuk monitor banjir;

- pemagaran batas tanah dan pelestarian lingkungan; dan

- pemasanganscrubber untuk mengatasi kebocoran tabung gas chlor.



Gambar 2.Upaya Pengamanan Kualitas (K1)

(a) Pemagaran dan pelestarian lingkungan; (b) perbaikan di area rekreasi; (c) pemasangan scrubber (Sumber: PDAM Kota Malang 2013, dan Observasi Lapangan 2017)

Tentunya, rencana perbaikan dilakukan agar menjaga kualitas air baku aman hingga ke konsumen sesuai yang dipersyaratkan; dan terjaga melalui pengawasan Dinas Kesehatan (eksternal) dan PDAM sebagai penyelenggara air minum (internal). Diharapkan dengan terjaganya kualitas air, tentunya dapat meningkatkan derajat kesehatan masyarakat.

Berdasarkan pengamanan yang telah dilakukan, maka dapat dikatakan bahwa PDAM Kota Malang telah mencapai aspek K1. Hal tersebut dibuktikan pula dengan penerapan Zona Air Minum Prima (ZAMP), yaitu air siap minum yang sudah memenuhi syarat untuk bisa diminum langsung dari kran air yang sudah terpasang di beberapa wilayah.

\subsection{Kuantitas (K2)}

Seiring dengan pertumbuhan jumlah penduduk, kebutuhan terhadap air akan semakin meningkat pula. Jumlah air yang dinilai mencukupi bagi kebutuhan masyarakat, diukur menggunakan standar Peraturan Menteri Pekerjaan Umum Nomor 01 Tahun 2014 tentang Standar Pelayanan Minimal Bidang Pekerjaan Umum dan Penataan Ruang, yaitu sebesar 10 
$\mathrm{m}^{3} / \mathrm{KK} /$ bulan atau 60 liter/orang/hari. Pada aspek K2, diperhitungkan persentase kehilangan air di sistem produksi, kehilangan air di sistem distribusi, dan jumlah kepala keluarga (KK) yang terlayani air bersih sebesar $10 \mathrm{~m}^{3} / \mathrm{KK} /$ bulan.

Kehilangan air di sistem produksi dan sistem distribusi di PDAM Kota Malang setiap tahunnya relatif menurun (Gambar 3). Berdasarkan data pada tahun 2013 - September 2017, kehilangan air produksi sebesar 22,75\%; 18,56\%; 18,45\%; 19,55\%; dan 6,55\%. Sedangkan, kehilangan air distribusi sebesar 34,88\%; 23,53\%; 28,47\%; 27,78\%; dan $16,56 \%$.

Sasaran kehilangan air di sistem produksi dan sistem distribusi yaitu $0 \%$, namun kenyataannya hal tersebut sulit terealisasikan. Penyebab kehilangan air di sistem produksi, salah satunya diakibatkan oleh penggunaan sehari-hari di PDAM yang menyebabkan air tidak seluruhnya terjual ke pelanggan (Pratama Putra, 2014). Sedangkan, kehilangan air di sistem distribusi, diantaranya kehilangan air fisik, seperti kebocoran di reservoir, kehilangan air di pipa transmisi maupun distribusi, atau pada sambungan rumah; dan kehilangan air non fisik, disebabkan karena keliru pada pembacaan meter air ( human error) dan pencurian air (Farley dkk, 2008).

Kejadian bahaya yang berdampak terhadap meningkatnya risiko pelayanan disistem produksi, yaitu kerusakan/alih fungsi lahan, pengaruh musim, water hammer, kerusakan pompa, dan permasalahan suplai listrik. Sedangkan di distribusi, yaitu kerusakan instalasi perpipaan, endapan lumpur di reservoir, dan meter air pelanggan tidak berfungsi sempurna (Perusahaan Daerah Air Minum Kota Malang, 2013). Upaya yang telah dilakukan PDAM Kota Malang untuk mengatasi kehilangan air, diantaranya :

- melakukan district metering;

- Standar Operasional Prosedur (SOP) deteksi kebocoran; dan

- monitoring yang terintegrasi online menggunakan Geographic Information System (GIS).

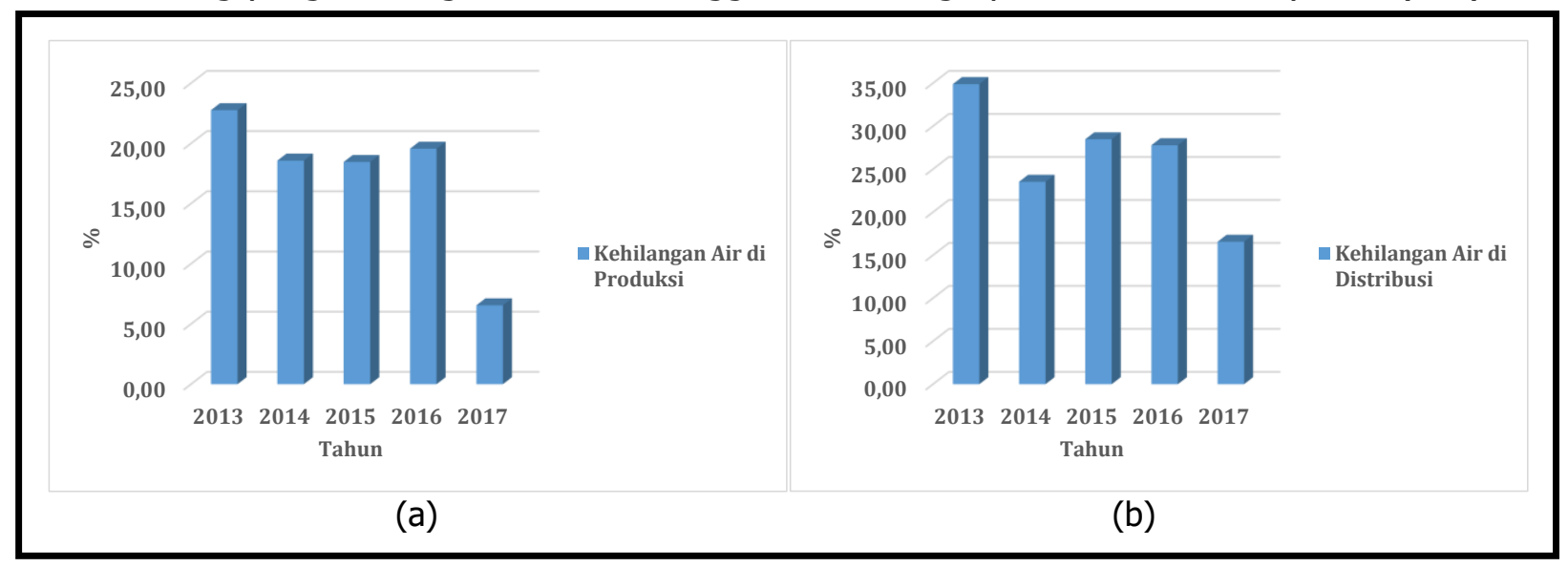

Gambar 3. Persentase Kehilangan Air di (a) Sistem Produksi dan (b) Sistem Distribusi (Sumber: PDAM Kota Malang, 2017)

Dilihat dari jumlah KK terlayani, total jumlah KK yang mendapatkan air $<10 \mathrm{~m}^{3} / \mathrm{KK} /$ bulan lebih kecil dibandingkan dengan total jumlah $\mathrm{KK}$ yang mendapatkan air $\geq 10 \mathrm{~m}^{3} / \mathrm{KK} / \mathrm{bulan}$. Hal tersebut membuktikan bahwa PDAM Kota Malang berhasil memberikan pelayanan yang maksimal kepada pelanggan dengan meminimalisir setiap hambatan dalam menjalankan strategi pelayanan pendistribusian air, meskipun belum mampu melayani hingga $100 \%$ pelanggannya. Hambatan dapat disebabkan oleh kondisi anggaran untuk pengembangan jaringan, kapasitas air, sistem informasi dan teknologi, dan Sumber Daya Manusia (SDM) (Puri, 2015). 
Sasaran aspek K2 di PDAM Kota Malang telah tercapai. Untuk menurunkan tingkat kehilangan air, maka melalui peran sistem online yang sudah dikembangkan PDAM Kota Malang sejak tahun 2014, sangat membantu dalam memonitoring dan mendokumentasikan RPAM dengan baik; sehingga tindakan pengendalian sesegera mungkin dapat dilakukan. Sedangkan, dari jumlah KK yang terlayani, semakin meningkatnya total jumlah KK setiap tahunnya yang mendapatkan air $\geq 10 \mathrm{~m}^{3} / \mathrm{KK} /$ bulan.

\subsection{Kontinuitas (K3)}

PDAM Kota Malang telah menerapkan lama pelayanan selama 24 jam/hari, sesuai dengan Peraturan Menteri Pekerjaan Umum dan Perumahan Rakyat Nomor 27 Tahun 2016 tentang Penyelenggaraan Sistem Penyediaan Air Minum; sehingga dapat dikatakan pelayanan terhadap pelanggannya sudah baik. Tentunya, dengan pengaliran tidak terputus selama 24 jam maka dapat membantu masyarakat dalam mendapatkan pasokan air; sehingga keuntungan pun akan diperoleh PDAM Kota Malang karena banyak air terjual dan meningkatkan kepercayaan pelanggan.

Begitupun dengan besarnya tekanan air di critical point minimal 0,5 bar sesuai dengan standar yang dipersyaratkan tersebut. Berdasarkan data pada tahun 2017, sebanyak 32.916 $\mathrm{KK}$ atau $21,14 \%$ dari total pelanggan sebanyak $155.705 \mathrm{KK}$ mendapatkan tekanan air minum $<0,5$ bar; dan sebanyak $122.789 \mathrm{KK}$ atau 78,86\% mendapatkan tekanan air minum > 0,5 bar. Hal tersebut menunjukkan bahwa pencapaian PDAM Kota Malang sudah cukup baik; meskipun masih harus melakukan upaya agar besarnya tekanan yang ada mampu memenuhi standar bagi seluruh pelanggannya agar tekanan yang diterima pelanggan cukup.

Kejadian bahaya di PDAM Kota Malang yang berdampak langsung terhadap lama pelayanan, salah satunya yaitu kerusakan pada pompa; dimana apabila kinerja pompanya buruk maka konsumen tidak mendapatkan air dengan debit dan tekanan yang cukup. Upaya yang telah dilakukan PDAM Kota Malang, yaitu menyediakan pompa cadangan danmonitoring rutin sesuai dengan jam operasi. Pencapaian aspek K3 di PDAM Kota Malang dapat dikatakan sudah tercapai; dimana adanya peran sistem logger onlineyang mengirimkan data hasil pengukuran tekanan di lapangan; sehingga dengan mudah dipantau langsung di kantor(Gambar 4).

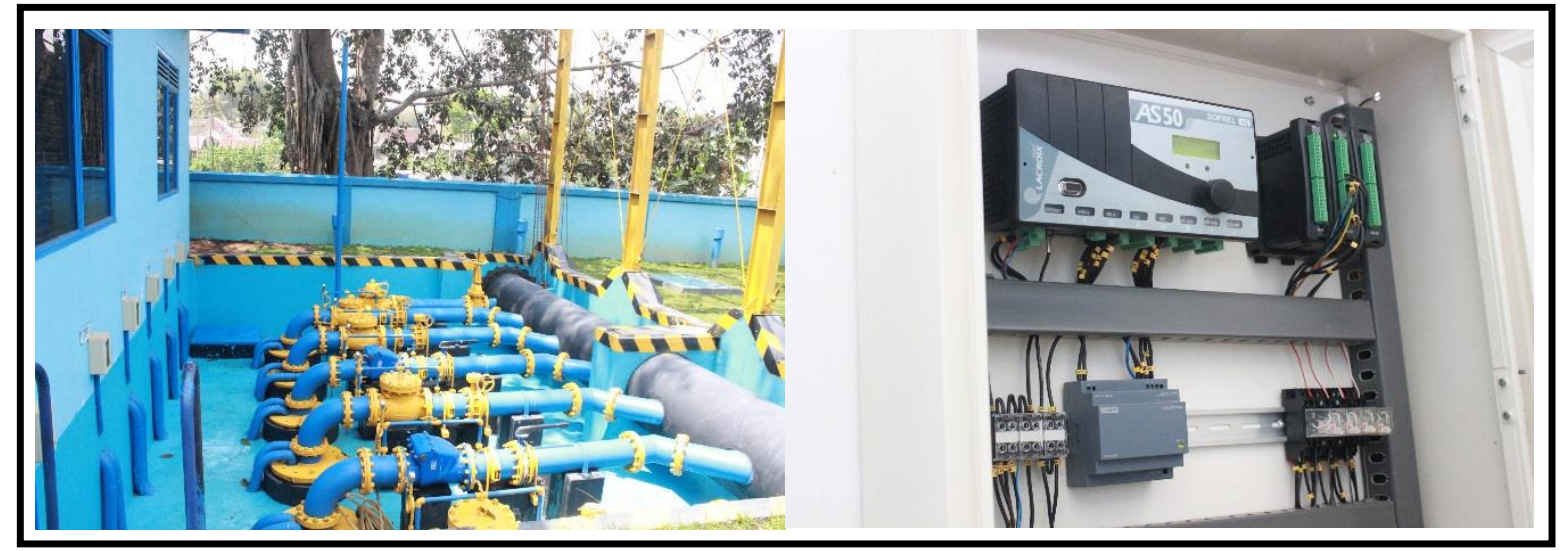

Gambar 4. Upaya Pengendalian Kontinuitas (K3) di Sumber Wendit

(Sumber: Observasi Lapangan, 2017)

\subsection{Keterjangkauan (K4)}

Aspek keterjangkauan (K4) berkaitan dengan nilai Upah Minimum Kota (UMK) untuk menetapkan tarif air minum yang layak bagi masyarakat. Tarif air minum yang ditetapkan 
berdasarkan standar Peraturan Menteri Dalam Negeri Nomor 71 Tahun 2016 tentang Perhitungan dan Penetapan Tarif Air Minum, tidak boleh melampaui 4\% dari UMK Kota Malang. Berdasarkan data PDAM Kota Malang untuk tahun 2013 - September 2017, tarif air bersih maupun air minum ditetapkan dengan nilai yang sama, yaitu sebesar Rp. 2.500; Rp. 2.500; Rp. 2.800; Rp. 3.000; dan Rp. 3.200. Penetapan tarif air tersebut tidak melampaui 4\% UMK; sehingga dapat dikatakan tarif tersebut telah sesuai yang dipersyaratkan dan secara aspek K4 sasarannya telah tercapai.

\subsection{Capaian RPAM}

Penerapan RPAM sudah dilaksanakan PDAM Kota Malang untuk mengamankan air minum dari sumber air baku sampai ke konsumen. Hasil evaluasi pelaksanaan ini secara umum menemukan bahwa sasaran terhadap aspek 4K di PDAM Kota Malang sudah terpenuhi. Hasil evaluasi tersebut berdasarkan pemeriksaan dokumen RPAM tahun 2013, 2014, 2015, dan 2016; dan pengecekan kondisi di lapangan; dimana PDAM Kota Malang telah melaksanakan beberapa tindakan pengendalian untuk mengatasi kejadian bahaya dan risiko dalam Sistem Penyediaan Air Minum (SPAM) PDAM Kota Malang.

Hingga saat ini, PDAM Kota Malang telah menerapkan program ZAMP(Gambar 5) sebagai perwujudan peningkatan pelayanan khususnya dalam peningkatan kualitas air (Perusahaan Daerah Air Minum Kota Malang, 2016). Cakupan pelayanan ZAMP pada tahun 2014 sudah mencapai 82\% wilayah Kota Malang (Haq, 2014). Program tersebut sebagai upaya penerapan dari standar yang dipersyaratkan; dimana air yang didistribusikan oleh PDAM harus berkualifikasi air minum.

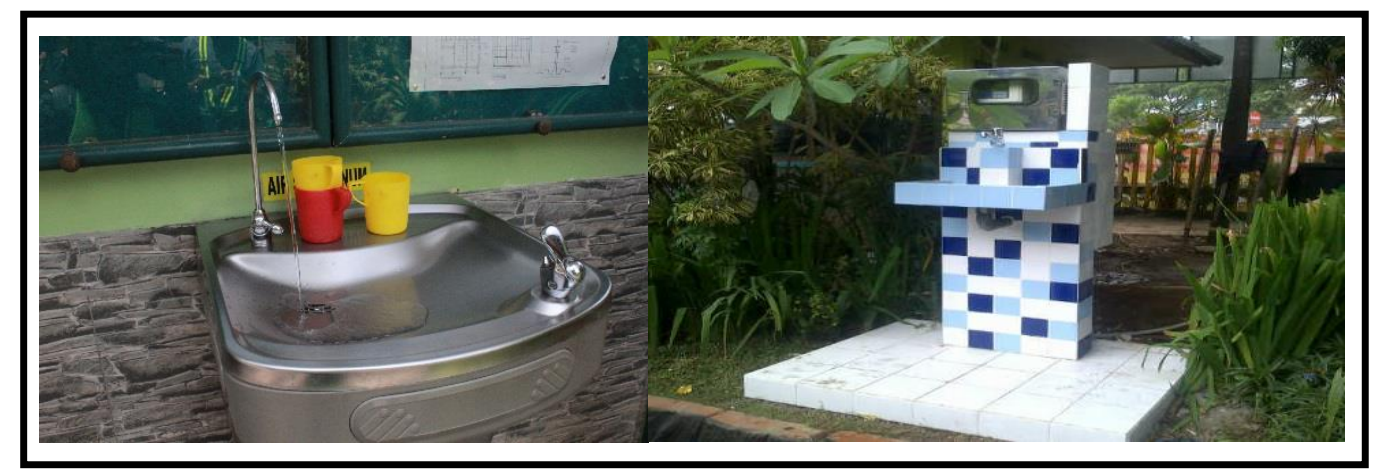

Gambar 5. Zona Air Minum Prima (ZAMP)

(Sumber: Observasi Lapangan, 2017)

Beberapa sistem yang digunakan untuk melakukan monitoring secara online, yaitu aplikasi RPAM, GIS RPAM, dan Water Utility Integrated Network; dimana sistem tersebut dapat dengan mudah memantau setiap kejadian bahaya yang ada di lapangan. Begitu kejadian bahaya terpantau, maka sistem secara otomatis menampilkan tindakan pengendalian dan Standard Operating Procedures (SOP) yang harus dilakukan, kemudian petugas di lapangan dapat melakukan verifikasi tutup kasus secara online bila rencana perbaikan sudah dilakukan.

\section{KESIMPULAN}

RPAM merupakan alat untuk meningkatkan efisiensi dan mencapai efektifitas pelayanan air minum, dengan melihat pencapaian terhadap aspek 4K. Berdasarkan hasil penelitian, PDAM Kota Malang telah menerapkan RPAM dengan baik dan memenuhi persyaratan 4K (kualitas, kuantitas, kontinuitas, dan keterjangkauan); dimana penerapan RPAM tersebut telah didukung oleh sistem online untuk memantau dan menindaklanjuti setiap kejadian 
bahaya.Berbagai upaya telah dilakukan PDAM Kota Malang, seperti pengamanan di sumber air baku untuk mempertahankan kualitas, perawatan teknis untuk menjaga kuantitas dan kontinuitas, dan tarif air yang ditetapkan masih dapat dijangkau oleh masyarakat dengan memperhitungkan UMK Kota Malang dan standar pelayanan minimum sebesar 10 $\mathrm{m}^{3} / \mathrm{KK} /$ bulan atau 60 liter/orang/hari.

\section{UCAPAN TERIMA KASIH}

Terima kasih kepada pihak PDAM Tirta Dharma Kota Malang yang telah mendampingi selama survei di lapangan, dan bersedia memberikan data yang dibutuhkan dalam penelitian ini.

\section{DAFTAR RUJUKAN}

Adiyanti, Dewi. (2016). Identifikasi Resiko pada Rencana Pengamanan Air Minum (RPAM) Operator untuk Sumber Air Permukaan di PDAM Tirta Raharja Kabupaten Bandung. REKA LINGKUNGAN, 4(2).

Arthana, I. W. (2007). Studi Kualitas Air Beberapa Mata Air di Sekitar Bedugul, Bali (The Study of Water Quality of Springs Surrounding Bedugul, BalI). Bumi Lestari, オ1).

Dinas Kependudukan dan Pencatatan Sipil Kota Malang. (2017). Profil Perkembangan Kependudukan Kota Malang Tahun 2016. Malang: Dinas Kependudukan dan Pencatatan Sipil.

Direktorat PU Cipta Karya. (2012). Manual Rencana Pengamanan Air Minum (RPAM)Operator.

Farley, M., Wyeth, G., Ghazali, Z., Istandar, A., Singh. (2008). The Managers Non Revenue Water Handbook: A Guide To Understanding Water Losses. USAID.

Haq, B., dan Masduqi, A. (2014). Sistem Distribusi Air Siap Minum PDAM Kota Malang: Studi Kasus Kecamatan Blimbing. Jurnal Teknik ITS, 3(2), D182-D187.

Peraturan Daerah Kotamadya Tingkat II Malang No. 11 tahun 1974 tentang Perusahaan Daerah Air Minum (PDAM) Kodya Dati II Malang.

Peraturan Menteri Dalam Negeri No. 71 Tahun 2016 tentang Perhitungan dan Penetapan Tarif Air Minum.

Peraturan Menteri Kesehatan No. 492 Tahun 2010 tentang Persyaratan Kualitas Air Minum.

Peraturan Menteri Pekerjaan Umum No. 01 Tahun 2014 tentang Standar Pelayanan Minimal Bidang Pekerjaan Umum dan Penataan Ruang.

Peraturan Menteri Pekerjaan Umum dan Perumahan Rakyat No. 27 Tahun 2016 tentang Penyelenggaraan Sistem Penyediaan Air Minum.

Perusahaan Daerah Air Minum (PDAM) Kota Malang. (2013). Laporan Rencana Pengamanan Air Minum. Malang: PDAM Kota Malang.

Perusahaan Daerah Air Minum (PDAM) Kota Malang. (2016). Monitoring dan Evaluasi RPAM PDAM Kota Malang. Malang: PDAM Kota Malang.

Pratama Putra, J. (2014). Studi Kehilangan Air pada Jaringan Distribusi PDAM di Jalan Soekarno-Hatta Palembang dengan Metode DMA ( District Meter Area ). Politeknik Negeri Sriwijaya.

Puri, D. K. (2015). Implementasi Strategi Perusahaan Daerah Air Minum dalam Peningkatan Pelayanan Pendistribusian Air (Studi pada Perusahaan Daerah Air Minum Kota Malang). Jurnal Administrasi Publik, 3(12), 2133-2138.

Suryo, Bagus. (2018). 'PDAM Kota Malang Raih Top PDAM 2018 dan Top BUMD 2018', Media Indonesia, 3 Mei. 